Trinity University

Digital Commons @ Trinity

Psychology Faculty Research

Psychology Department

2021

\title{
The Availability of Training Opportunities in Personality Disorders in American Psychological Association- and Psychological Clinical Science Accreditation System-Accredited Clinical and Counseling Psychology Doctoral Programs
}

\author{
K. N. Levy \\ William D. Ellison \\ Trinity University, wellison@trinity.edu
}

Follow this and additional works at: https://digitalcommons.trinity.edu/psych_faculty

Part of the Psychology Commons

Publication Details

Training and Education in Professional Psychology

\section{Repository Citation}

Levy, K. N., \& Ellison, W. D. (2021). The availability of training opportunities in personality disorders in American Psychological Association- and Psychological Clinical Science Accreditation System-accredited clinical and counseling psychology doctoral programs. Training and Education in Professional Psychology. http://doi.org/10.1037/tep0000376

This Post-Print is brought to you for free and open access by the Psychology Department at Digital Commons @ Trinity. It has been accepted for inclusion in Psychology Faculty Research by an authorized administrator of Digital Commons@ Trinity. For more information, please contact jcostanz@trinity.edu. 
The availability of training opportunities in personality disorders in APA- and PCSASaccredited clinical and counseling psychology doctoral programs

Kenneth N. Levy

The Pennsylvania State University

William D. Ellison

Trinity University

Author Note: Kenneth N. Levy, Department of Psychology, Pennsylvania State University;

William D. Ellison, Department of Psychology, Trinity University. Correspondence concerning this article should be addressed to Kenneth N. Levy, Department of Psychology, Pennsylvania State University, 362 Bruce V. Moore Building, University Park, PA 16803. E-mail:

klevy@psu.edu. Phone: 814-865-5848. Fax \# 814-863-7002.

(C) 2021, American Psychological Association. This paper is not the copy of record and may not exactly replicate the final, authoritative version of the article. Please do not copy or cite without authors' permission. The final article will be available, upon publication, via its DOI: 10.1037/tep0000376

Kenneth N. Levy, PhD, is an associate professor of psychology at The Pennsylvania State University, where he teaches Clinical Methods focused on contemporary treatments for personality disorders, and directs the Laboratory for Personality, Psychopathology, and 
Psychotherapy Research. He received his doctorate from The Graduate School and University Center at the City University of New York and completed a clinical internship and postdoctoral training at the New York Presbyterian Hospital at the Joan and Sanford I. Weill Medical College of Cornell University. His research and professional interests include attachment theory, personality and personality disorders, psychotherapy processes and outcome, and professional ethical issues related to evidence based training and mental health literacy.

William D. Ellison, $\mathrm{PhD}$, is an assistant professor of psychology at Trinity University. He received his doctorate from The Pennsylvania State University and completed a clinical internship at the Massachusetts Mental Health Center/Beth Israel Deaconess Medical Center, Harvard Medical School. He completed postdoctoral training at Rhode Island Hospital, Warren Alpert Medical School of Brown University. His research and professional interests include personality and personality disorders, the use of ecological momentary assessment in research and psychotherapy, and psychotherapy outcome for borderline personality disorder. 


\begin{abstract}
Personality disorders are relatively common, especially in clinical settings. A number of evidence-based treatments are now available, especially for borderline personality disorder.

However, little is known about the relevant training available to doctoral students in clinical and counseling psychology. in the current study, data were extracted from 336 clinical and counseling Ph.D. and Psy.D. programs from the Insider's Guide to Graduate Programs in Clinical and Counseling Psychology (Norcross \& Sayette, 2020), including the number of programs with faculty with specific interests in personality disorders and the number of programs with clinical opportunities related to personality disorders. We found that formal training in personality disorders is not widely available to most trainees in APA-accredited doctoral training programs. Only $16 \%$ of programs have faculty with interests in personality disorders, all of them clinical psychology programs. Ph.D. programs were more likely to have PD-interested faculty than Psy.D. programs, and, within clinical Ph.D. programs, PCSASaccredited programs were more likely to have PD-interested faculty than programs without PCSAS accreditation. Similarly, only $15 \%$ of programs (all clinical psychology programs) offer practicum opportunities in psychotherapy for personality disorders. Our findings indicate that doctoral level psychology programs are not sufficiently preparing their students with personality disorder training, which serves as a substantial disservice to both trainees and the public.

Keywords: Clinical Psychology, Counseling Psychology, Ph.D., Psy.D., Personality disorders, Training.
\end{abstract}

\title{
Public Significance Statement
}

This study found that training in personality disorders at APA-accredited clinical and counseling doctoral programs is not available to a level commensurate with the prevalence and severity of the problem. This was particularly true among Psy.D. programs and even more so counseling 
programs. Although training in personality disorders was statistically more likely to be available at APA-accredited programs that were also PCSAS-accredited, most of these programs, regardless of accreditation, also lacked faculty with declared expertise and/or specified clinical training opportunities in personality disorders. As a profession, we are at risk of not providing needed research and clinical training. 


\section{The availability of training opportunities in personality disorders in APA- and PCSAS- accredited clinical and counseling psychology doctoral programs}

Personality disorders (PDs) represent a major public health concern and as such merit priority in the training of psychologists (Levy, in Magnavita et al., 2010). Most definitions of personality disorders stress that they are a group of related disorders characterized by longstanding patterns of intra- and interpersonal difficulties (Levy \& Johnson, 2016). Research shows that personality disorders are highly prevalent, commonly comorbid, and quite disruptive, painful, and even deadly. For example, results from general population epidemiological surveys across more than 20 countries and six continents have found prevalence rates for DSM defined personality disorders ranging between $4.4 \%$ and $21.5 \%$ (with most studies ranging between 911\%; see Winsper et al., 2019). Prevalence rates are generally much higher in clinical populations, with studies using structured diagnostic assessments finding that between $20-45 \%$ of psychiatric outpatients and 45-50\% of inpatients meet criteria for a personality disorder (Korzekwa, Dell, Links, Thabane, \& Webb, 2008; Kovanicova, Kubasovska, \& Pallayova, 2020; Marinangeli et al., 2000; Zanarini et al., 2004; Zimmerman, Rothschild, \& Chelminski, 2005).

Not only are personality disorders prevalent on their own, but they are also commonly comorbid with a range of disorders, such as bipolar disorder, depression, anxiety disorders, eating disorders, post-traumatic stress disorder and substance abuse disorders (Zanarini et al., 1998) and health conditions (El-Gabalawy, Katz,\& Sareen, 2010; Sansone, Pole, Dakroub et al., 2006). This comorbidity is especially meaningful in that the presence of a personality disorder negatively affects the course and outcome of these disorders, leading to lower rates of remission and increased rates and shorter times to relapse, prolongs the length of treatment, and reduces treatment efficacy of otherwise effective treatments for these disorders (Bieling, Green, \& 
MacQueen, 2007; Cloitre \& Koenen, 2001; Levenson, Wallace, Fournier, Rucci, \& Frank, 2012; Mennin \& Heimberg, 2000; see Newton-Howes, Tyrer, \& Johnson, 2006).

Personality disorders are also associated with high rates of both non-suicidal self-injury and suicidality, especially among those with borderline and narcissistic personality disorders (Temes et al., 2019). Recent meta-analyses suggest that completed suicide rates for those with borderline personality disorder (BPD) are about $8 \%$, which is higher than the individual rates for schizophrenia (4.0\%), depression (3.6\%), eating disorders $(2.3 \%)$, bipolar disorder $(1.3 \%)$, and post-traumatic stress disorder (PTSD) (0.4\%) (Chesney et al., 2014; Palmer et al., 2005; Pompili, Girardi, Ruberto, \& Tatarelli, 2005; Pompili et al., 2004). Personality disorders are also striking sources of social cost, family burden, morbidity and all-cause mortality (Hastrup et al., 2019; Temes et al., 2019; Tyrer, Tyrer, \& Yang, 2019; Quirk et al., 2016) and place considerable pressure on the mental health care system (Bender et al., 2001).

Historically, personality disorders have been thought to be difficult to diagnose. However, many studies have now found good reliability for the assessment of personality pathology — equivalent or superior to most DSM defined disorders (Chmielewski, Clark, Bagby, \& Watson, 2016; Zanarini et al., 2000). Moreover, emerging prototypal and dimensional diagnostic systems for personality disorders may aid in reliable diagnosis (Garcia et al., 2018), as does increased knowledge about differential diagnosis (Pilkonis, Heape, Ruddy, \& Serrao, 1991). Still, despite several reliable and well validated evidence-based assessment measures, including screening measures and semi-structured interviews that display good psychometric properties (Widiger \& Samuel, 2005), personality disorders are under recognized. Findings from several studies suggest that clinicians do not diagnose personality disorders in ordinary clinical practice (Barbato \& Hafner, 1998; Zimmerman \& Mattia, 1999). 
Over the last few decades, there has also been an increasingly robust empirical literature suggesting that personality disorders, especially BPD, are treatable with a range of specialty therapies deriving from the cognitive-behavioral and psychodynamic traditions (Budge et al., 2013; Cristea et al., 2017). In addition, there are a number of adjunctive interventions and modules and generalist approaches that have been developed and show good results (Ellison, 2020). Thus, there are a wide variety of evidence-based psychosocial interventions for personality disorders that can be taught in clinical psychology training programs.

Thus, the imperative to train future psychologists in evidence-based practice entails the inclusion of personality disorders in the graduate curriculum. We see this curriculum as consisting of two parts: first, the inclusion of evidence-based assessment and intervention approaches for personality disorders in the didactic and practical coursework required of doctoral psychology students; and second, where possible, the inclusion among program faculty of individuals with research programs focusing on personality pathology. As to the first component, as we have indicated above, there is solid evidence that specialized treatments for PDs, especially BPD, outperform treatment-as-usual (Ellison, 2020). This makes the availability of specialty therapy training for PDs especially important (Crits-Cristoph, Chambless, \& Markell, 2014). The second component, that of faculty research interest in PDs, may seem like a secondary concern. Nevertheless, we believe that having faculty with research interests in PDs serves the immediate function of bolstering student knowledge of the clinical features of PDs, their epidemiology, course and prognosis, and their treatment outcomes, thus contributing to the integration of science and practice and enhancing the entrainment of evidence-based practice for PDs (Beck et al., 2014; Castonguay, 2011). Moreover, the representation of PD experts on a 
program's faculty sends a signal to students that personality pathology is important and worthy of appropriate clinical consideration.

Despite the psychological and financial toll of personality disorders on the individual and society, the availability of several evidence-based treatments, and an identified public health need (Beatson, 2019; Iliakis et al., 2019; Lazzari et al., 2018), specialized training in researching, identifying, and treating personality disorders in mental health training programs has lagged behind training in other forms of psychopathology. For example, Levy (in Magnavita, 2010) reviewed doctoral psychology programs accredited by the American Psychological Association (APA) using data from Norcross, Sayette, and Mayne's (2008) Insider's Guide to Graduate Programs in Clinical and Counseling Psychology, which surveyed 319 programs about faculty interest and expertise and opportunities for specialized training in specific clinical areas. Only 24 (7.5\%) of these programs reported having a faculty member with expertise in personality disorders and only seven programs (2\%) indicated that they had specialized clinical training in personality disorders. By contrast, 80 programs $(25 \%)$ had a faculty member with stated expertise in anxiety disorder (a 176 total faculty members) and 23 programs (7\%) had a specialty clinic for treating anxiety disorder. The disparity between the number of programs with faculty and training that specialize in personality disorders versus anxiety disorders is notable considering the prevalence in outpatients is similar for the two disorder categories (Remes, Brayne, van der Linde, \& Lafortune, 2016).

Since this study, there has been little follow-up. Although there are a few reports on implementing training in personality disorders in psychology department clinics (Noll, Lewis, Zalewski, Martin, Roos, Musser, \& Reinhardt, 2019; Rizvi, Hughes, Hittman, \& Vieira Oliveira, 2017) and several more within residency programs (for example Bernstein, Zimmerman \& 
Auchincloss, 2015; Unruh \& Gunderson, 2016; Zerbo, Cohen, Bielska, \& Caligor, 2013), we did not find empirical reports of the scope of training in personality disorders in clinical psychology programs beyond those in Magnavita et al. (2010).

The present study sought an updated estimate of the extent to which APA-accredited clinical and counseling psychology doctoral programs offered training in personality disorders. In addition, we examined programs accredited by an alternative accreditation body, the Psychological Clinical Science Accreditation System (PCSAS), which since 2010 has emerged as an alternative to the APA-accrediting system. ${ }^{1}$ Lastly, we examined differences in training offered as a function of type of degree (Ph.D. vs. Psy.D.), type of program (Clinical vs. Counseling), and accrediting body (APA vs. PCSAS).

We hypothesized that:

(1) the majority of doctoral programs in clinical and counseling psychology would not offer any explicit training in personality disorders. This hypothesis follows from the findings from Magnavita et al. (2010)

(2) to the extent training is offered, faculty interested in personality disorders and training opportunities in personality disorders would be more likely to occur in PhD programs as compared to PsyD programs. This was also based on findings from Magnavita et al.

\footnotetext{
${ }^{1}$ For ease of writing and conceptual reasons we refer to the distinction between programs accredited by the APA and PCSAS as APA-accredited and PCSAS-accredited. Although it is important to note that currently all PCSASaccredited programs are also accredited by the APA. Referring to PCSAS-accredited programs as APA/PCSAS programs, although technically correct, would be cumbersome. Similarly, referring to APA-accredited programs as APA/non-PCSAS-accredited programs would also be cumbersome. More relevant is that fact that many PCSASaccredited programs (e.g., University of Arizona, UC Berkeley, UCLA, Indiana University, University of Illinois Urbana-Champaign, University of Delaware, University of Wisconsin-Madison, University of South Florida, and Stony Brook University) have publicly announced that their training mission is consistent with the standards of PCSAS and that they will not renew their APA-accreditation once it expires. Some programs (e.g., UC Berkeley) have gone as far to inform their current applicants that although APA-accredited, newly admitted students enter into a PCSAS-accredited clinical science program and that entry into the APA-accredited program is no longer available.
} 
(3) clinical programs would be more likely than counseling programs to have faculty who study personality disorders and offer training opportunities in personality disorders, because clinical programs focus more on psychopathology and counseling programs more on issues of wellbeing (Morgan \& Cohen, 2008; Sayette \& Norcoss, 2020).

(4) a higher percentage of programs with PCSAS accreditation would have faculty with research interests in PDs than programs with only APA accreditation, because of the focus of the former on clinical science; and a higher percentage of programs with only APA accreditation would offer clinical training in PDs than PCSAS- accredited programs, given the stronger focus of the former on clinical training.

(5) and finally, that faculty representation and training opportunities in personality disorder would lag behind that of other disorders with similar prevalence rates and even disorders with lower prevalence rates, based on the findings from Magnavita et al..

\section{Method}

\section{Sampling and Procedures}

The authors extracted data from the current edition of the Insider's Guide to Graduate Programs in Clinical and Counseling Psychology (Norcross \& Sayette, 2020), which included data from 336 APA-accredited clinical and counseling PhD and PsyD programs. The data on a range of program, faculty, and student characteristics are provided by the directors of clinical training programs and are collected during the spring and summer every 2 years beginning in 1991 and through 2019. The data are then published the next year. Thus, the data in the current study were collected in 2019 and published in the 2020-2021 edition. In the current edition, the response rate was 99\% (Norcross \& Sayette, 2020). For the purposes of the current study, 
specific program information extracted included data on the number of faculty with specific interests in personality disorders and the number of programs with specialty clinics and practicum experiences for working with personality disorders. Programs were counted as having faculty with an interest in personality disorders if they appeared in either the "personality disorders" or "antisocial personality disorder" categories, which were separate in the latest edition of the Insider's Guide. Other faculty interest categories tallied for comparison's sake were mood disorders (represented by the "affective disorders/depression/mood disorders" category in the Insider's Guide), substance use disorder ("alcohol" and "substance abuse/addictive behaviors"), anxiety disorders/panic ("anxiety disorders/panic disorders" and “obsessive-compulsive disorder”), PTSD (“posttraumatic stress disorder/trauma”), eating disorders ("eating disorders/body image"), autism spectrum disorder ("autism/Asperger's syndrome/developmental disorders"), and psychotic disorders ("schizophrenia" and "severe mental illness").

\section{Data Analytic Plan}

Hypothesis 1 was examined by frequency counts. For hypotheses 2, 3, and 4, chi-square analyses and Fisher's exact tests were performed on categorical variables to examine differences between programs. Hypothesis 5 was evaluated using z-tests for proportions.

\section{Results}

\section{Descriptive Findings}

Of the 336 APA-accredited programs in Norcross and colleagues (2020) Insider's Guide, 248 were Ph.D. programs (174 clinical PhD programs, 67 Counseling PhD programs, 1 combined clinical-school PhD program, 3 combined Counseling-school PhD programs, and 3 combined clinical-counseling $\mathrm{PhD}$ programs, the last of which were deemed clinical for the 
purposes of this manuscript) and 87 were Psy.D. programs ( 73 clinical PsyD programs, 9 counseling Psy.D. programs, 4 clinical-school combined Psy.D. programs, one counselingschool combined Psy.D. program, and one clinical-health combined Psy.D. program). At the time of data extraction there were 43 doctoral programs that also had PCSAS accreditation, of which all were clinical Ph.D. programs.

Of the 336 APA-accredited programs, only 55 (16.4\%) programs indicated that they had a faculty member interested in personality disorders. This represents a $129 \%$ increase in the number of programs with such faculty interest over the twelve-year period from the publication of Magnavita et al. (2010). Nevertheless, despite this increase, fewer than one in six programs reported having any faculty with interest in personality disorders. Fifty programs (14.9\%) also reported the availability of a PD-related specialty clinic or practicum opportunity, with 22 other programs reporting a practicum opportunity in dialectical behavior therapy (DBT), which is a specialty treatment originally designed for BPD but has also been applied to several other diagnoses. $^{2}$

\section{Characteristics of Programs Offering Training in Personality Disorders}

Table 1 shows the characteristics of doctoral psychology programs offering research and clinical training in PDs. All 55 APA-accredited programs that report having at least one faculty member with interest in personality disorders were clinical programs. None of the counseling or combined programs reported having a faculty member with interest in personality disorders.

Similarly, only two of the specialty clinic/practicum training opportunities were associated with

\footnotetext{
${ }^{2}$ Although DBT was originally developed for borderline personality disorder, it has also been used to treat other disorders, such as eating disorders, substance use disorders, PTSD, and impulsive-spectrum disorders, and thus it was not clear from the Insider's Guide which disorders a program's clinic was using DBT to treat. Thus, it was not counted here as a specialty treatment for PDs. Nonetheless, sensitivity analyses in which programs offering DBT specialty clinics were counted among those with specialty clinics for PDs only suggested one substantive change to our conclusions (see below).
} 
counseling programs, with an additional four combined programs reporting a specialty clinic/practicum. There were no differences between Ph.D. and Psy.D. programs in the availability of faculty with interest in personality disorders or specialty clinics/practicum opportunities. However, because none of the counseling psychology programs had faculty members with interest in personality disorders and because most Psy.D. programs (91\%) are clinical psychology programs we wondered if an association between faculty with interest in personality disorders and Ph.D status as hypothesized was being washed out by the inclusion of counseling programs. Thus, a post-hoc chi-square analysis was conducted comparing Ph.D. and Psy.D. programs with a focus on only clinical psychology programs. For this comparison, the difference in percent of programs with a faculty member with interest in personality disorders was significant $\left(\chi^{2}[\mathrm{df}=1, N=247]=4.99, p=0.03\right)$. Thus, this hypothesis was not supported when counseling programs are included, but is supported when examined within clinical psychology programs. Regarding PCSAS-accredited programs, they were more likely to have both faculty interested in PDs and clinical training opportunities in personality disorders.

\section{Personality Disorders vs. Other Disorders}

Although the majority of doctoral programs in clinical and counseling psychology do not report faculty representation in the study of personality disorders or report any explicit training in personality disorders, it is possible that the situation is not different for other disorders. Thus, programs' reports of the number of faculty with interest in mood disorders, anxiety disorders, eating disorders, posttraumatic disorders, and substance use disorders were also examined.

Figure 1 shows the percentage of faculty with interests in other disorder categories, as well as the number of specialty clinics and practicum opportunities for other disorder categories in training programs. For comparison, this figure also presents the established 12-month prevalence of each 
disorder category in the community (Hudson, Hiripi, Pope, \& Kessler, 2007; Kessler, Birnbaum, et al., 2005; Kessler, Chiu, Demler, Merikangas, \& Walters, 2005; Maenner et al., 2020; Trull, Jahng, Tomko, Wood, \& Sher, 2010). The proportions of programs with faculty members with interests in anxiety disorders, substance use disorders, mood disorders, and PTSD were all significantly greater than the proportion of programs with faculty with PD interests, $(p$-values < $.001)$. In contrast, psychotic disorders $(p=.81)$, eating disorders $(p=.31)$, and autism spectrum disorder $(p=.95)$ had representation of faculty within programs that did not significantly differ from that of personality disorders. There were also fewer specialty training clinics or practicum opportunities for PDs than for substance use disorders, PTSD, anxiety disorders, and mood disorders $(p$-values $<.02)$, but not for eating disorders $(p=.39)$, autism spectrum disorder $(p=$ $.48)$, or psychotic disorders $(p=.81) .^{3}$

\section{Discussion}

The current study sought to examine the availability of training opportunities in PDs at APA-accredited clinical and counseling Ph.D. and Psy.D. doctoral programs and PCSASaccredited programs. The overall rates of faculty with interest in PDs and specialty practicum and externship training in personality disorders was low for both Ph.D and Psy.D. degrees and within clinical and counseling programs. The meager availability extent of training in personality disorders in counseling programs is particularly striking and would suggest that trainees graduating from such programs leave training for internship with a significant gap in their knowledge. The situation is only slightly better for those graduating from clinical psychology Psy.D. programs and non-PCSAS accredited clinical Ph.D. programs, although the situation is

\footnotetext{
${ }^{3}$ If DBT is counted as a specialty treatment for PDs but not for other diagnoses, all conclusions are substantively identical except that the difference between the availability of specialty treatment for PDs is no longer significantly different from that for PTSD $(p=.55)$.
} 
significantly better for PCSAS-accredited clinical psychology Ph.D. programs. For the most part, APA-accredited programs are not providing adequate pre-internship training regarding a frequently occurring clinical problem. Little is known about the likelihood of psychology trainees receiving such training while on internship. Future research should examine this question.

Research indicates that in routine practice clinicians fail to diagnose many personality disorder cases. The current study suggests that one reason that personality disorders go undiagnosed is that our trainees may not be not adequately prepared to recognize them. Related, Thompson, Mashhood, Nesci, and Rao (2015) found that early career psychiatrists reported that their training was not very useful when dealing with personality disordered patients across a broad array of areas, including case formulation, risk management, prescribing medication, team dynamics, informing clients/families about diagnosis, providing psychotherapy, and managing emergency room visits. It is likely that psychology trainees graduating from APA-accredited clinical and counseling psychology programs would report similar difficulties.

One might hypothesize that the lack of training available in personality disorders is a general problem - perhaps training programs also lack faculty with expertise in other forms of psychopathology and psychotherapy. However, the number of training opportunities in personality disorders was between a third and a half of what was available compared to substance/alcohol/tobacco use disorders, PTSD, mood disorders, and anxiety disorders. The number of faculty with interest in personality disorders was about the same as was available for psychotic disorders, autism, and eating disorders, despite the much lower prevalence rates for those disorders. Thus, faculty with interest in personality disorders and clinical training opportunities in personality disorders were among the least common, despite the relatively high 
prevalence of PD's. In sum, although we found that the availability of training in personality disorders has increased substantially over the past decade, we also found considerable evidence that the importance of training in personality disorders is underappreciated, especially when bearing in mind the prevalence of personality disorders and their lethality.

Although much of the focus in this article thus far has been on clinical consequences, the neglect in training on personality disorders also has implications for conducting valid research on other psychological disorders and difficulties. Psychopathology research itself may be hampered if comorbid personality disorders go unrecognized. For example, initial studies suggested that individuals with panic disorder and anxiety symptoms are at increased risk for suicidality (Weissman et al., 1989; Lepine et al. 1993), but later studies that included measures of personality pathology found that PD's, aggression, and impulsivity accounted for this association (Placidi et al., 2000; Warshaw et al., 2000). It is also possible that the lack of faculty research expertise in personality disorders will exacerbate the scarcity of quality clinical training in PDs by stifling the growth of the evidence base for interventions.

Although the findings from this study have a number of important implications for doctoral training in clinical and counseling psychology, there are several limitations that should be addressed in future work. Because we relied on data from a published survey, we were unable to explore specific personality disorders or whether personality disorders were a primary interest to faculty. Additionally, we were unable to determine whether other training opportunities were provided in coursework or to document available clinical training opportunities that are not part of a specialty clinic or a practicum experience. Additionally, there may be tenure-line and/or non-tenure-line faculty with clinical expertise that is not represented by research interests. Thus, there may be some underestimation of available training opportunities. Nonetheless, it is unlikely 
that a large amount of training went undetected, especially without the requisite faculty expertise, and programs would probably have little incentive to underreport the expertise of their faculty on a survey that will be published as a guide to prospective program applicants. Moreover, PD expertise was relatively underrepresented in psychology training faculty compared to other disorder categories with equivalent or lower prevalence and burden of disease, suggesting that underreporting is unlikely to account entirely for current findings. Nonetheless, it would be useful for future research in this area to examine program content more directly to better determine the extent of training offered.

Additionally, it will be important to examine which specific personality disorders are the focus of faculty research interest, as well as which specific treatments are represented in the available clinical training. Findings from several studies (e.g., Boschen \& Warner, 2009; Sibai \& Huprich, 2019) examining the content of publications on personality disorders suggest that those who study borderline and antisocial personality disorder may be best represented, but these overall publication rates may not accurately reflect the full extent of faculty expertise in psychology doctoral programs. With regard to training in specific evidence-based treatments, there are several treatments available to clinicians, especially for borderline personality disorder, such as DBT, Transference-Focused Psychotherapy (TFP), Mentalization-Based Treatment (MBT), Schema Therapy (ST), and others. Among these, only DBT is given its own training category in the Insider's Guide. Over two decades ago, Crits-Christoph et al. (1995) found that 17 of 138 programs (12\%) provided training in DBT. In the current study, only a slightly higher percentage of surveyed programs had a specialty clinic or practicum experience focused on personality disorders or DBT combined, and the availability of training in other specific treatments is unclear. Given the negligible differences in outcome among various approaches in 
treating personality disorders (see Cristea et al., 2017), it would be useful to know specific details about the training opportunities available to students beyond DBT.

\section{Implications of Findings}

The results of the current study found that formal training in personality disorders through mentorship opportunities with faculty or through specialty clinics or practicum experiences are not widely available to most trainees in APA-accredited doctoral training programs. This level of neglect regarding PDs among accredited doctoral training programs in doctoral training programs, particularly in counseling psychology, is inconsistent with evidencebased practice. Given the prevalence of personality disorders, their comorbidity, the negative consequences of said comorbidity for course and outcome, and their lethality, and given the availability of evidence-based psychological treatments and assessment tools for personality disorders, it is incumbent upon our discipline to provide instruction and training in the identification and treatment of personality disorders to our trainees. It is difficult to imagine how we are to adequately train students for contemporary practice without such training. We recommend that programs strongly consider addressing this gap between the needs of students and patients and the training provided. A review of curriculum, relevant colloquia, and supplemental training might be considered initial steps, as well as greater efforts to identify PD cases in clinical training (e.g., through screening, structured assessments, and attending to comorbidity). We would further argue that properly addressing the gap requires greater efforts to hire relevant faculty. At a systemic level, APA and PCSAS might consider addressing this need through their processes of accreditation. 


\section{References}

Barbato, N., \& Hafner, R. J. (1998). Comorbidity of bipolar and personality disorder. Australasian Psychiatry, 32(2), 276-280.

Beatson, J. (2019). Making psychological treatments for borderline personality disorder available. Australasian Psychiatry, 27, 545-547.

Beck, J. G., Castonguay, L. G., Chronis-Tuscano, A., Klonsky, E. D., McGinn, L. K., \& Youngstrom, E. A. (2014). Principles for training in evidence-based psychology: Recommendations for graduate curricula in clinical psychology. Clinical Psychology: Science and Practice, 21, 410-424.

Bender, D. S., Dolan, R. T., Skodol, A. E., Sanislow, C. A., Dyck, I. R., McGlashan, T. H., ... Gunderson, J. G. (2001). Treatment utilization by patients with personality disorders. American Journal of Psychiatry, 158(2), 295-302.

Bieling, P. J., Green, S. M., \& MacQueen, G. (2007). The impact of personality disorders on treatment outcome in bipolar disorder: A review. Personality and Mental Health, 1, 2-13.

Boschen, M. J., \& Warner, J. C. (2009). Publication trends in individual DSM personality disorders: 1971-2015. Australian Psychologist, 44, 136-142.

Budge, S. L., Moore, J. T., Del Re, A. C., Wampold, B. E., Baardseth, T. P., \& Nienhuis, J. B. (2013). The effectiveness of evidence-based treatments for personality disorders when comparing treatment-as-usual and bona fide treatments. Clinical Psychology Review, 33(8), 1057-1066.

Castonguay, L. C. (2011). Psychotherapy, psychopathology, research and practice: Pathways of connections and integration. Psychotherapy Research, 21(2), 125-140.

Chesney, E., Goodwin, G. M., \& Fazel, S. (2014). Risks of all-cause and suicide mortality in mental disorders: a meta-review. World Psychiatry, 13(2), 153-160. 
Chmielewski, M., Clark, L. A., Bagby, R. M., \& Watson, D. (2016). Method matters: Understanding diagnostic reliability in DSM-IV and DSM-5. Journal of Abnormal Psychology, 124(3), 764-769. doi:10.1037/abn0000069

Cloitre, M. \& Koenen, K. C. (2001) The impact of borderline personality disorder on process group outcome among women with posttraumatic stress disorder related to childhood abuse. International Journal of Group Psychotherapy, 51, 379-398.

Cristea, I. A., Gentili, C., Cotet, C. D., Palomba, D., Barbui, C., \& Cuijpers, P. (2017). Efficacy of psychotherapies for borderline personality disorder: A systematic review and metaanalysis. JAMA Psychiatry, 74(4), 319-328. doi: 10.1001/jamapsychiatry.2016.4287.

Crits-Cristoph, P., Chambless, D. L., \& Markell, H. M. (2014). Moving evidence-based practice forward successfully: Commentary on Laska, Gurman, and Wampold. Psychotherapy, 51(4), 491-495. doi:10.1037/a0036508

El-Gabalawy, R., Katz, L.Y., Sareen, J. (2010). Comorbidity and associated severity of borderline personality disorder and physical health conditions in a nationally representative sample. Psychosomatic Medicine, 72, 641-647.

Ellison, W. D. (2020). Psychotherapy for borderline personality disorder: Does the type of treatment make a difference? Current Treatment Options in Psychiatry. Advance online publication.

Garcia, D. J., Skadberg, R. M., Schmidt, M., Bierma, S., Shorter, R. L., \& Waugh, M. H. (2018). It's not that difficult: An interrater reliability study of the DSM-5 Section III Alternative Model for Personality Disorders. Journal of Personality Assessment, 100(6), 612-620. doi:10.1080/00223891.2018.1428982 
Hastrup, L. H., Jennum, P., Ibsen, R., Kjellberg, J., Simonsen E. (2019). Societal costs of Borderline Personality Disorders: a matched-controlled nationwide study of patients and spouses. Acta Psychiatrica Scandinavica 140:5, 458-467.

Hudson, J. I., Hiripi, E., Pope, H. G., \& Kessler, R.C. (2007). The Prevalence and Correlates of Eating Disorders in the National Comorbidity Survey Replication. Biological Psychaitry, 6, 348-358

Iliakis, E.A., Sonley, A. K. I., Ilagan, G. S., Choi-Kain, L. W., (2019). Treatment of borderline personality disorder: Is supply adequate to meet public health needs? Psychiatric Services, 70(9), 772-781.

Kessler RC, Chiu WT, Demler O, Merikangas KR, Walters EE. (2005). Prevalence, severity, and comorbidity of 12-month DSM-IV disorders in the National Comorbidity Survey Replication. Archives of General Psychiatry,62(6), 617-627.

Kessler RC, Birnbaum H, Demler O, Falloon IR, Gagnon E, Guyer M, Howes MJ, Kendler KS, Shi L, Walters E, Wu EQ. (2005). The prevalence and correlates of nonaffective psychosis in the National Comorbidity Survey Replication (NCS-R). Biological Psychiatry, 15;58(8), 668-676.

Korzekwa, M. I., Dell, P. F., Links, P. S., Thabane, L., \& Webb, S. P. (2008). Estimating the prevalence of borderline personality disorder in psychiatric outpatients using a two-phase procedure. Comprehensive Psychiatry, 49, 380-386.

doi:10.1016/j.comppsych.2008.01.007

Kovanicova, M., Kubasovska, Z., \& Pallayova, M. (2020). Exploring the presence of personality disorders in a sample of psychiatric inpatients. Journal of Psychiatry and Psychiatric Disorders, 4(3), 118-129. doi:10.26502/jppd.2572-519X0099 
Lamers, F., van Oppen, P., Comijs, H. C., Smit, J. H., Spinhoven, P., van Balkom, A. J. L. M., ...Penninx, B. W. J. H. (2011). Comorbidity patterns of anxiety and depressive disorders in a large cohort study: The Netherlands Study of Depression and Anxiety (NESDA). Journal of Clinical Psychiatry, 72(3), 341-348.

Lazzari, C., Shoka, A., Papanna, B., \& Kulkarni, K. (2018). Current healthcare challenges in treating the borderline personality disorder "epidemic.” British Journal of Medical Practitioners, 11(2), a1112.

Lepine, J. P., Chignon, J. M., \& Teherani, M. (1993). Suicide attempts in patients with panic disorder. Archives of General Psychiatry, 50, 144-149.

Levenson, J. C., Wallace, M. L., Fournier, J. C., Rucci, P., \& Frank, E. (2012). The role of personality pathology in depression treatment outcome with psychotherapy and pharmacotherapy. Journal of Consulting and Clinical Psychology, 80(5), 719-729.

Levy, K. N., Johnson, B. N., (2016) Personality disorders. In Norcross, J. C., Vanden, G. R., Freeheim, D. K. APA Handbook Of Clinical Psychology (173-207). Washington D.C: American Psychological Association.

Maenner MJ, Shaw KA, Baio J, et al. (2020). Prevalence of Autism Spectrum Disorder Among Children Aged 8 Years - Autism and Developmental Disabilities Monitoring Network, 11 Sites, United States, 2016. MMWR Surveill Summary, 69(No. SS-4):1-12. http://dx.doi.org/10.15585/mmwr.ss6904a1external icon.

Magnavita, J. J., Levy, K. N., Critchfield, K. L., \& Lebow, J. L. (2010). Ethical considerations in treatment of personality dysfunction: Using evidence, principles, and clinical judgment. Professional Psychology: Research and Practice, 41(1), 61-74 
Marinangeli, M. G., Butti, G., Scinto, A., Cicco, L. D., Kalyvoka, A., Petruzzi, C., \& Rossi, A. (2000). A personality disorders prevalence study among inpatients with mood disorders, psychoactive substance use disorders and anxiety disorders. Epidemiologia e Psichiatria Sociale, 9(01), 36-44. https://doi.org/10.1017/S1121189X00007739

Mennin, D. S., \& Heimberg, R. G. (2000). The impact of comorbid mood and personality disorders in the cognitive-behavioral treatment of panic disorder. Clinical Psychology Review, 20, 339-357.

Morgan, R. D., \& Cohen, L. M. (2008). Clinical and counseling psychology: Can differences be gleaned from printed recruiting materials? Training and Education in Professional Psychology, 2(3), 156-164. https://doi.org/10.1037/1931-3918.2.3.156

Newton-Howes, G., Tyrer, P., \& Johnson, T. (2006). Personality disorder and the outcome of depression: Meta-analysis of published studies. British Journal of Psychiatry, 188(1), 1320.

Noll, L. K., Lewis, J., Zalewski, M., Martin, C. G., Roos, L., Musser, N., \& Reinhardt, K. (2019). Initiating a DBT consultation team: Conceptual and practical considerations for training clinics. Training and Education in Professional Psychology, 14(3), 167-175.

Norcross, J. C., \& Sayette, M. A. (2020). Insider's Guide to Graduate Programs in Clinical and Counseling Psychology: 2020/2021 Edition. New York: Guilford Press.

Norcross, J. C., Sayette, M. A., Mayne, T. J. (2008) Insider's Guide to graduate Programs in Clinical and Counseling Psychology (2008/2009 ed.). New York: The Guilford Press.

Palmer, B. A., Pankratz, V. S., \& Bostwick, J. M. (2005). The lifetime risk of suicide in schizophrenia: A reexamination. Archives of General Psychiatry, 62, 247-253. 
Pilkonis, P., Heape, C., Ruddy, J., \& Serrao, P. (1991). Validity in the diagnosis of personality disorders: The use of the LEAD standard. Psychological Assessment: A Journal of Consulting and Clinical Psychology, 3(1), 46-54.

Placidi, GPA, Oquendo, MA, Malone, KM, Brodsky, B, Ellis, SP, \& Mann, JJ (2000). Anxiety in major depression: Relationship to suicide attempts. American Journal of Psychiatry, 157: 1614-1618.

Pompili, M., Mancinelli, I., Girardi, P., Ruberto, A., \& Tatarelli, R. (2004). Suicide in anorexia nervosa: A meta-analysis. International Journal of Eating Disorders, 36(1), 99-103.

Pompili, M., Girardi, P., Ruberto, A., \& Tatarelli, R. (2005). Suicide in borderline personality disorder: A meta-analysis. Nordic Journal of Psychiatry, 59(5), 319-324.

Quenqua, D. (August 2013). Seeing narcissists everywhere. The New York Times. http://www.nytimes.com/2013/08/06/science/seeing-narcissistseverywhere.html.

Quirk, S. E., Berk, M., Chanen, A. M., Koivumaa-Honkanen, H., Bernnan-Olsen, S., Pasco, J. A., \& Williams, L. J. (2016). Population prevalence of personality disorder and associations with physical health comorbidities and health care service utilization: A review. Personality Disorders: Theory, Research, and Treatment, 7(2), 136-146.

Remes, O., Brayne, C., van der Linde, R., \& Lafortune, L. (2016). A systematic review of reviews on the prevalence of anxiety disorders in adult populations. Brain and Behavior, 6(7), e00497. doi:10.1002/brb3.497

Rizvi, S. L., Hughes, C. D., Hittman, A. D., \& Vieira Oliveira, P. (2017). Can trainees effectively deliver dialectical behavior therapy for individuals with borderline personality disorder? Outcomes from a training clinic. Journal of Clinical Psychology, 73, 1599 1611. doi:10.1002/jclp.22467 
Sansone, R. A., Pole, M., Dakroub, H., \& Butler, M. (2006). Childhood trauma, borderline personality symptomatology, and psychophysiological and pain disorders in adulthood. Psychosomatics, 47(2), 158-162.

Sibai, M., \& Huprich, S. (2019). An 11-Year Review of Personality Disorder Frequencies in Peer Reviewed Journals. ISSPD

Temes, C. M., Frankenburg, F. R., Fitzmaurice, G. M., \& Zanarini, M. C. (2019). Deaths by suicide and other causes among patients with borderline personality disorder and personality-disordered comparison subjects over 24 years of prospective follow-up. The Journal of Clinical Psychiatry, 80(1), 18m12436. doi:10.4088/JCP.18m12436

Thompson, K., Mashhood, A., Nesci, J., Rao, S. (2015). Where should the borders of psychiatry training be? The need for more emphasis on borderline personality disorder. Australasian Psychiatry, 21 182-84.

Trull TJ, Jahng S, Tomko RL, Wood PK, Sher KJ. (2010). Revised NESARC personality disorder diagnoses: gender, prevalence, and comorbidity with substance dependence disorders. Journal of Personality Disorders, 24, 412-426.

Tyrer, P., Tyrer, H., \& Yang, M. (2019). Premature mortality of people with personality disorder in the Nottingham Study of Neurotic Disorder. Personality and Mental Health. Advance online publication. doi:10.1002/pmh.1466

Unruh, B. T., \& Gunderson, J. G. (2016). Good enough psychiatric residency training in borderline personality disorder: Challenges, choice points and a model generalist curriculum. Harvard Journal of Psychiatry, 24(5), 367-377. https:// doi.org/10.1097/HRP.0000000000000119 
Warshaw, MG, Dolan, RT, \& Keller, MB (2000). Suicidal behavior in patients with current or past panic disorder: Five years of prospective data from the Harvard/Brown Anxiety Research Program. American Journal of Psychiatry 157: 1876-1878.

Weissman MM, Klerman GL, Markowitz JS, et al: (1989). Suicidal ideation and suicide attempts in panic disorder and attacks. New England Journal of Medicine 321: 12091214.

Widiger, T. A., \& Samuel, D. B. (2005). Evidence-based assessment of personality disorders. Psychological Assessment, 17(3), 278-287.

Winsper, C., Bilgin, A., Thompson, A., Marwaha, St. Chanen, A. M., Singh, S. P., Wang, A., \& Furtado, V. (2019). The prevalence of personality disorders in the community: A global systemic review and meta-analysis. The British Journal of Psychiatry, 216, 1-10.

Zanarini, M. C., Frankenburg, F. R., Dubo, E. D., Sickel, A. E., Trikha, A., Levin, A., \& Reynolds, V. (1998). Axis I comorbidity in borderline personality disorder. The American Journal of Psychiatry, 155(12), 1733-1739.

Zanarini, M. C., Frankenburg, F. R., Hennen, J., \& Silk, K. R. (2004). Mental health service utilization by borderline personality disorder patients and Axis II comparison subjects followed prospectively for 6 years. Journal of Clinical Psychiatry, 65(1), 28-36.

Zanarini, M. C., Skodol, A. E., Bender, D., Dolan, R., Sanislow, C., Schaefer, E., Morey, L. C., Grilo, C. M., Shea, M. T., McGlashan, T. H., \& Gunderson, J. G. (2000). The Collaborative Longitudinal Personality Disorders Study: Reliability of Axis I and Axis II diagnoses. Journal of Personality Disorders, 14(4), 291-299. 
Zerbo E, Cohen S, Bielska W, Caligor E (2013). Transference-focused psychotherapy in the general psychiatry residency: A useful and applicable model for residents in acute clinical settings. Psychodynamic Psychotherapy, 41(1), 163-181.

Zimmerman, M., \& Mattia, J. I. (1999). Differences between clinical and research practices in diagnosing borderline personality disorder. American Journal of Psychiatry, 156(10), 1570-1574.

Zimmerman, M., Rothschild, L., \& Chelminski, I. (2005). The prevalence of DSM-IV personality disorders in psychiatric outpatients. American Journal of Psychiatry, 162(10), 1911-1918. 


\section{Table 1}

Characteristics of Doctoral Training Programs Offering Faculty Research and Specialized Clinical Training in Personality Disorders

\begin{tabular}{llll}
\hline Characteristic & PD Faculty & No PD Faculty & Tests of independence \\
\hline Clinical & 55 & 192 & $\chi^{2}=20.4, p<0.001^{*}$ \\
Counseling & 0 & 76 & $\varphi=0.25$ \\
& & & \\
Ph.D. & 45 & 203 & $\chi^{2}=2.08, p=0.15$ \\
Psy.D. & 10 & 77 & $\varphi=0.08$ \\
& & & \\
PCSAS-accredited & 17 & 26 & $\chi^{2}=6.10, p=.01 * *$ \\
non-PCSAS & 28 & 107 & $\varphi=0.19$ \\
\hline \hline & PD specialty clinic & No PD specialty clinic & \\
\hline Clinical & 47 & 199 & $\chi^{2}=12.21, p<.001 *$ \\
Counseling & 2 & 74 & $\varphi=0.19$ \\
& & & \\
Ph.D. & 19 & 213 & $\chi^{2}=0.00, p=1.00$ \\
Psy.D. & 13 & 76 & $\varphi=0.00$ \\
PCSAS-accredited & 18 & & $\varphi$ \\
non-PCSAS & 19 & &
\end{tabular}

*Based on Fisher's Exact Test

**Comparison based on clinical psychology Ph.D. programs only 


\section{Figure 1}

Availability of Faculty with Research Interests in Different Disorder Categories and Specialty

Clinics for Disorders in APA-Approved Psychology Training Programs $(N=336)$ and

Prevalence of Disorders in the Community

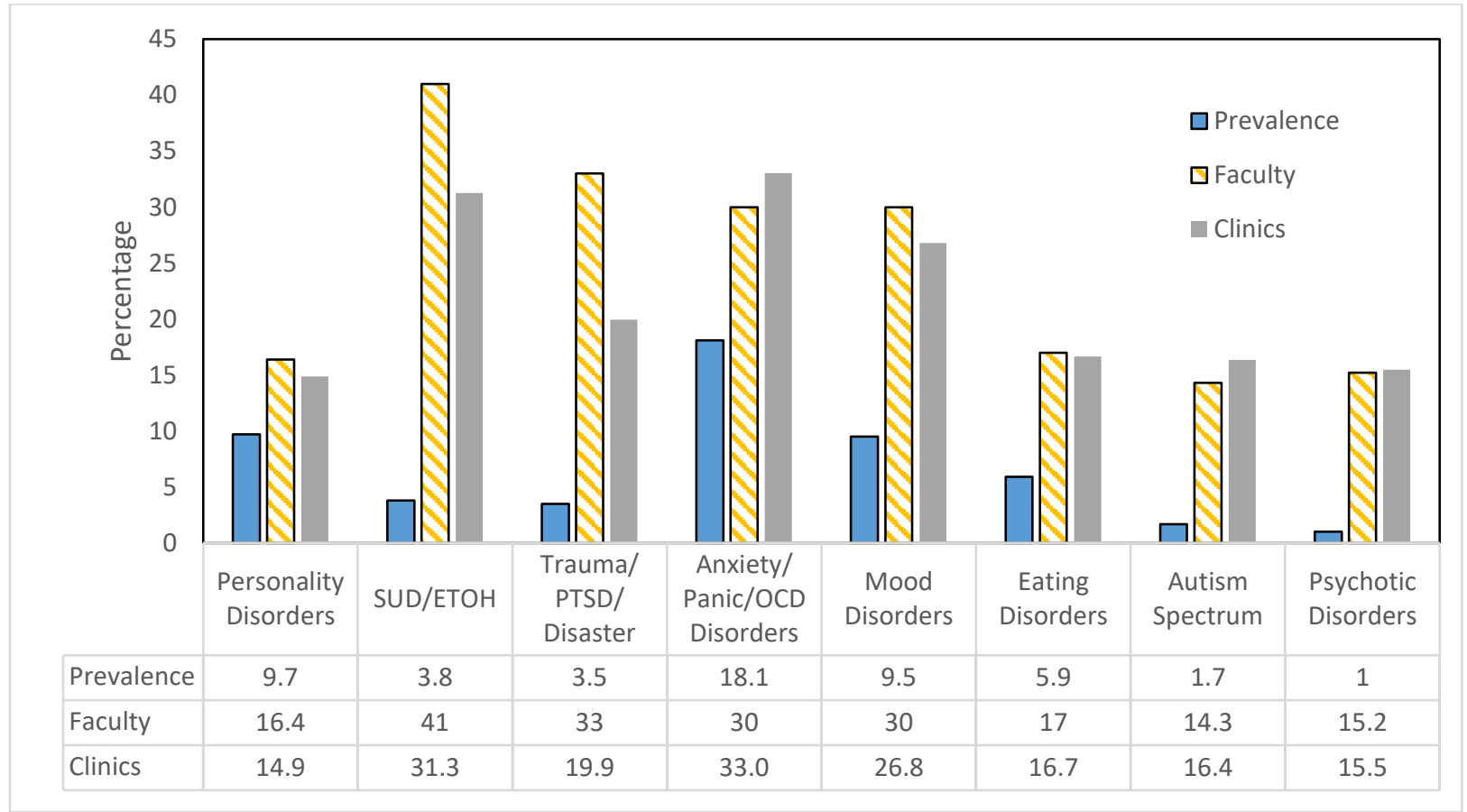

Note. Blue (dark solid) bars indicate the 12-month community prevalence of the disorder category. Orange (striped) bars indicate the percentage of APA-accredited doctoral training programs in psychology with faculty with research interests in the disorder category. Gray (light solid) bars indicate the percentage of doctoral training programs in psychology with specialty clinics or practicum sites for the disorder category.

\section{References for prevalence rates:}

a Trull TJ, Jahng S, Tomko RL, Wood PK, Sher KJ. (2010). Revised NESARC personality disorder diagnoses: gender, prevalence, and comorbidity with substance dependence disorders. Journal of Personality Disorders, 24, 412-426.

b Kessler RC, Chiu WT, Demler O, Merikangas KR, Walters EE. (2005). Prevalence, severity, and comorbidity of 12-month DSM-IV disorders in the National Comorbidity Survey Replication. Archives of General Psychiatry,62(6), 617-627. PMID: 15939839

c Hudson, J. I., Hiripi, E., Pope, H. G., \& Kessler, R.C. (2007). The Prevalence and Correlates of Eating Disorders in the National Comorbidity Survey Replication. Biological Psychaitry, 6, 348358 
d Maenner MJ, Shaw KA, Baio J, et al. (2020). Prevalence of Autism Spectrum Disorder Among Children Aged 8 Years - Autism and Developmental Disabilities Monitoring Network, 11 Sites, United States, 2016. MMWR Surveill Summary, 69(No. SS-4):1-12.

DOI: http://dx.doi.org/10.15585/mmwr.ss6904a1external icon.

e Kessler RC, Birnbaum H, Demler O, Falloon IR, Gagnon E, Guyer M, Howes MJ, Kendler KS, Shi L, Walters E, Wu EQ. (2005). The prevalence and correlates of nonaffective psychosis in the National Comorbidity Survey Replication (NCS-R). Biological Psychiatry, . 15;58(8), 668676. PMID: 16023620 